ORIGINAL ARTICLE

\title{
Facilities and equipment in district general hospitals in the Netherlands: Are we prepared for the critically ill paediatric patients?
}

\author{
N Van der Lely, P J C van Marion, J Otto, J A Hazelzet, H A Büller
}

Emerg Med J 2004;21:61-64

See end of article for authors' affiliations

.....................

Correspondence to: Dr N Van der Lely, Department of Paediatrics, Reinier de Graaf Gasthuis, Reinier de Graaf weg 11, 2625 AD Delft

Netherlands; lely@rdgg.nl

Accepted for publication 2 October 2003

\begin{abstract}
Objective: To evaluate the inventory for initial treatment of critically ill children.
Design: Prospective study.

Setting: Paediatric emergency settings in 15 major district general hospitals.

Methods: Using an "expert opinion" created by paediatric intensivists, all hospitals were visited twice to check the inventory. Firstly, to examine the initial site of emergency care for children coming from outside the hospital. Secondly, to visit other emergency sites. A total score below $75 \%$ of the optimum was considered as not optimally equipped.

Main results: Equipment to meet "respiratory problems" was considered by the experts as most essential. Seventy five per cent of all emergency sites scored below $75 \%$ (4 of 11 paediatric departments, 1 of 15 emergency rooms. The emergency room was in all aspects significantly better equipped than the paediatric department. Major differences and variations in the inventory were identified between all hospitals.

Conclusions: Emergency rooms are better equipped to meet the needs of critically ill paediatric patients coming from outside the hospital than the paediatric departments. Paediatricians involved in the treatment of children who become critically ill during their stay in the hospital (the "indoor" patients), have less equipment and medication on the paediatric department at their disposal than on their emergency room. Obviously, emergency care on the paediatric wards should be equipped at the same level as in the emergency room because for both locations the "golden hour" is critically important in final outcome.
\end{abstract}

$\mathrm{S}$ tudies have affirmed that cooperation among district general hospitals in a region as well as with the tertiary, academic centre is essential for adequate patient care, optimal exchange of knowledge, and initiatives of improving care for that region. ${ }^{1-3}$ Out of this broad recognition of the need for improved care of critically ill children, recommendations and guidelines were developed. ${ }^{4-6}$ In fact, in some areas of the medical field, regionalisation has already been implemented such as for neonatal, burn and trauma patients, resulting in strongly improved outcomes of care. ${ }^{278}$ The Committee on Hospital Care of the American Academy of Pediatrics provided guidelines for equipping a paediatric unit in community hospitals. ${ }^{9}$ Many children who become acutely and/or critically ill are primarily admitted to a district general hospital. ${ }^{9}$ Analysing data regarding the type of illness and initial treatment in these hospitals is essential for the evaluation of care (submitted data). In the Netherlands, such critically ill children, coming from outside the hospital will, in general, present to the emergency room (ER) of the district general hospital. Adults as well as children can be treated in such ERs. However, some critically ill children will primarily be seen on the paediatric department (PD). Apart from patients becoming critically ill outside the hospital, sometimes patients on the PD need emergency care. The availability of medical material and medication in the ER and in the PD of these district general hospitals will provide an impression of the quality of care that can be provided on site. The presence of adequate material and medications is a prerequisite for optimal care and reflects the quality of care for the initial "golden hour" in the treatment of such children.

In the south west of the Netherlands paediatricians developed guidelines to optimise and regionalise paediatric health care in general. A committee was installed, comparable to the Committee on Paediatric Emergency Medicine of the American Academy of Pediatrics, which produced lists of resources, necessary to assure good health care in the district general hospitals in the region. ${ }^{4}$ The primary purpose of the Dutch regional committee was to compose a list of medical material and medication that was necessary for an inventory in a room where initial treatment of critically ill children would take place. The result of their work was a list of 29 "general" resources like a spinal needle; 25 items to meet "circulatory" problems such as intra-osseous infusion needles, and 23 items to meet "respiratory" problems such as different bag-valve devices and laryngoscope blades. After approval, the list was distributed in the early 1990s among all paediatricians in the area. In a "consensus report for regionalisation of services for critically ill or injured children", published recently, three components integration of care of critically ill children were mentioned. ${ }^{6}$ These three parts of regionalisation were defined as "categorisation", "accreditation", and "designation" of given care. As part of my thesis entitled "emergency care for critically ill children in district general hospitals", an assessment of the inventory at the different emergency sites was performed. We believe that controlling the facilities on the presence of the items, mentioned in the different guidelines is an essential part of management of a regionalised system of care for the critically ill.

The main purpose was to evaluate whether or not the emergency facilities were adequately prepared to provide

Abbreviations: ER, emergency room; PD, paediatric department 
optimal care in the "golden hour" of treatment for the critically ill children. To our knowledge no such study has been performed previously.

\section{METHODS}

The study was conducted in the year 1999 in 15 major district general hospitals in the south west of the Netherlands, encompassing 4 million inhabitants over an area of $8000 \mathrm{~km}^{2}$ with one academic hospital (fig l). To study the presence of medical material and medication, we visited within one day all hospitals, using the list for medical equipment and medication that was created and distributed by the regional paediatric committee. The aim was to evaluate the various items in the room, designated by the local paediatrician as the locality to start the first phase of treatment of a critically ill child coming from outside the hospital. Three teams consisting of two researchers visited five hospitals each. The three teams were led by an experienced physician/research nurse, all trained in the same manner for scoring the different items. One day before evaluation, permission was asked from the local paediatricians for the site visit by telephone and through a letter, sent by fax, explaining the procedure. All hospitals agreed and the results were analysed anonymously.

Some paediatricians primarily used the ER of their hospital for the initial treatment while others preferred a "special room" in their PD for emergency care. On a second visit all the remaining sites for emergency care were visited using the same procedure. This made it possible to compare the inventory of the various emergency facilities for treating critically ill children.

For the interpretation of the results, 14 paediatric intensivists working in all parts of the Netherlands in different hospitals and trained in different academic hospitals, were asked before the visits took place, by means of a questionnaire to give their opinion about the necessity of the presence of various items in an emergency room. In the Netherlands paediatric intensivists are most experienced in the initial treatment of critically ill children in contrast with emergency physicians. They were asked to indicate if the

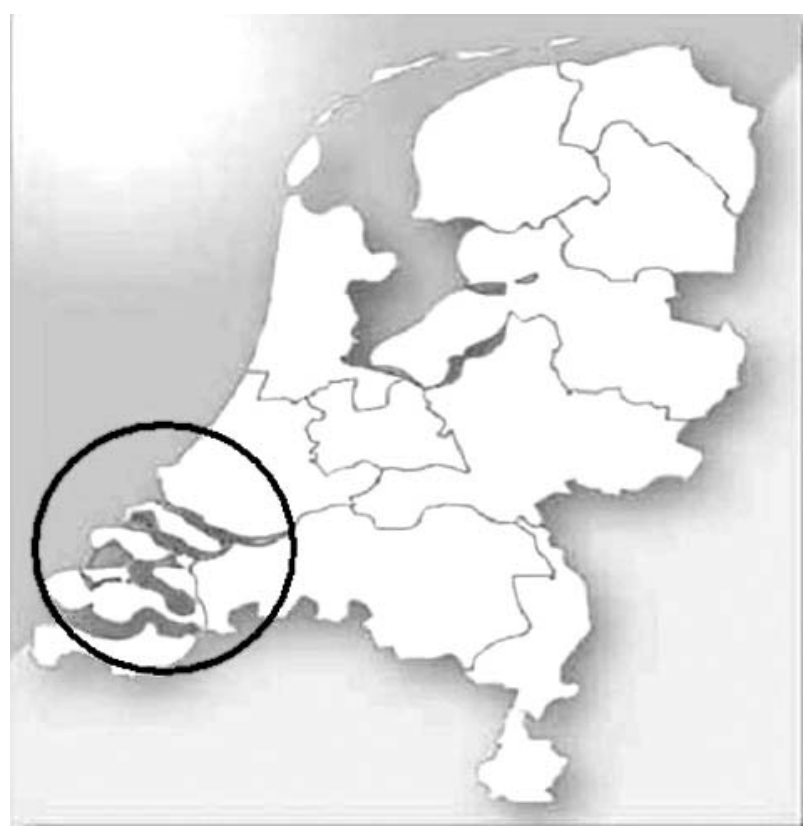

Figure 1 South west part of the Netherlands, encompassing 4 million inhabitants over an area of $8000 \mathrm{~km}^{2}$ with one academic paediatric hospital. presence was "handy" (score 1 point), necessary (score 3 points), or "essential" (score 5 points). The average scoring per item was used as "expert opinion". The content of the different facilities in the hospitals could thus be scored using the "expert opinion" score per item as an optimum. All facilities with a total score below $75 \%$ of the optimum were considered as not optimally equipped. This arbitrary cut off was chosen to allow for variation per hospital. Ideally you would opt for higher percentages closer to the expert's optimum.

\section{RESULTS}

Eleven of the 14 paediatric intensivists who received the questionnaire responded and their scoring resulted in the "expert opinion". Given the expert opinion, the different item groups could be assessed in terms of importance. Even within the groups, the importance of the presence of the different items could be further quantified. The higher the mean score, the more essential its presence was in the emergency facility. The different items were grouped as follows: total, general, respiratory, circulatory, and medication. The items in the group "respiratory resources" were considered as most essential (4.97), directly followed by "medication" (4.73), "circulatory resources" (4.62), and "general resources" (4.03) (see appendix 1 on the journal web site http://www. emjonline/supplemental). The experts considered most items in the "circulatory group" as essential. Only the presence of central venous lines, winged needle infusion sets, and needles to use for a "Port a Cath" were considered of less importance. In the group "medication" there was little diversity, only medication to treat "neurological" problems and "intoxication" was considered as not truly essential. All local paediatricians in the 15 hospitals, who were asked to participate, agreed to the visit. Assessing each hospital, the presence of the various items at the different emergency sites differed greatly (table 1). Hospital numbers 4, 6, 8, and 13 only used their ER for treatment of critically ill children coming from outside the hospital. In these hospitals there was not such a facility on their paediatric ward. All ERs except one (hospital number 4) were, regarding the total score, sufficiently equipped ( $>75 \%$ of the experts opinion) in comparison with 7 of 11 PDs. When breaking up the total score in the different groups a diverse picture emerged. Only 10 facilities (nine ERs and one PD) of the total 26 had sufficient general resources at site. All facilities, except five (all PDs) had a presence score of more than $75 \%$ of the optimum in the group of "respiratory resources". The same was found for "circulatory resources" except for two facilities with scores below 75\% (also all PDs). For the medication group, sufficient levels of the items were found in most cases except for three facilities (1 ER and 2 PDs), with two scoring comparatively low. In 10 of 15 ERs $100 \%$ of the essential medication was available in contrast with 1 of 11 PDs. In the hospitals number 11 and 12 the PD emergency facility scored for the total as well as for the different groups below $75 \%$ of the optimum. For hospital numbers 9 and 14 the total score for the room on the ward was below $75 \%$ but this was attributable to low scoring in general resources and respiratory resources. Comparing the scores within the hospitals, remarkable differences were found in percentages. Of the 11 hospitals with both ER and PD facilities for the treatment of critically ill children, only hospital number 3 had a higher presence of all items in the PD than in their ER. In the other 10 hospitals the ER was better equipped for the care of critically ill children. Some hospitals, like number 11 and 12, scored rather low on the PD in all groups while they had an adequate score in their ER. Comparing ERs with PDs within the different hospitals, a significant difference in the 
Table 1 Analysis of the presence of all items per group in the emergency rooms (ER) and paediatric departments (PD) in the 15 district general hospitals in south west of the Netherlands

\begin{tabular}{|c|c|c|c|c|c|c|c|c|c|c|c|}
\hline \multirow{3}{*}{$\begin{array}{l}\text { Expert opinion } \\
\text { Hospital }\end{array}$} & \multirow[b]{3}{*}{ Department } & \multirow{3}{*}{$\begin{array}{l}\text { Total(84) } \\
\text { points } \\
379.7\end{array}$} & \multirow{3}{*}{$\begin{array}{l}\% \\
100\end{array}$} & \multicolumn{2}{|c|}{$\begin{array}{l}\text { General response } \\
\text { (29) }\end{array}$} & \multicolumn{2}{|c|}{$\begin{array}{l}\text { Respiratory response } \\
(23)\end{array}$} & \multicolumn{2}{|c|}{$\begin{array}{l}\text { Circulatory response } \\
\text { (25) }\end{array}$} & \multirow{2}{*}{\multicolumn{2}{|c|}{$\begin{array}{l}\text { Medication (7) } \\
\text { Total points \% }\end{array}$}} \\
\hline & & & & Total points & $\%$ & Total points & $\%$ & Total points & $\%$ & & \\
\hline & & & & 116.9 & 100 & 114.3 & 100 & 115.4 & 100 & 33.1 & 100 \\
\hline \multirow[t]{2}{*}{1} & ER & 319.2 & 84.1 & 80.3 & 68.7 & 114.3 & 100.0 & 96.5 & 83.6 & 28.1 & 84.9 \\
\hline & PD & 298.0 & 78.5 & 72.9 & 62.4 & 92.7 & 81.1 & 104.3 & 90.4 & 28.1 & 84.9 \\
\hline \multirow[t]{2}{*}{2} & ER & 306.9 & 80.8 & 80.0 & 68.4 & 99.7 & 87.2 & 99.1 & 85.9 & 28.1 & 84.9 \\
\hline & PD & 299.1 & 78.8 & 74.5 & 63.7 & 106.4 & 93.1 & 90.1 & 78.1 & 28.1 & 84.9 \\
\hline \multirow[t]{2}{*}{3} & ER & 319.3 & 84.1 & 82.4 & 70.5 & 101.1 & 88.5 & 107.7 & 93.3 & 28.1 & 84.9 \\
\hline & PD & 329.5 & 86.8 & 92.4 & 79.0 & 104.7 & 91.6 & 104.3 & 90.4 & 28.1 & 84.9 \\
\hline 4 & $\begin{array}{l}E R \\
P D\end{array}$ & 284.0 & 74.8 & 71.6 & 61.3 & 90.0 & 79.5 & 99.1 & 85.9 & 23.3 & 70.5 \\
\hline \multirow[t]{2}{*}{5} & ER & 314.6 & 82.9 & 74.0 & 63.3 & 99.8 & 87.3 & 107.7 & 93.3 & 33.1 & 100.0 \\
\hline & PD & 290.3 & 76.5 & 82.7 & 70.7 & 82.5 & 72.2 & 97.0 & 84.1 & 28.1 & 84.9 \\
\hline 6 & $\begin{array}{l}E R \\
P D\end{array}$ & 321.5 & 84.7 & 74.5 & 63.7 & 104.8 & 91.7 & 109.1 & 94.5 & 33.1 & 100.0 \\
\hline \multirow[t]{2}{*}{7} & ER & 353.7 & 93.2 & 98.6 & 84.3 & 109.3 & 95.6 & 112.7 & 97.7 & 33.1 & 100.0 \\
\hline & PD & 319.5 & 84.1 & 79.2 & 67.8 & 96.6 & 84.5 & 110.6 & 95.8 & 33.1 & 100.0 \\
\hline 8 & $\begin{array}{l}E R \\
P D\end{array}$ & 320.6 & 84.4 & 99.4 & 85.0 & 99.6 & 87.1 & 88.5 & 76.7 & 33.1 & 100.0 \\
\hline \multirow[t]{2}{*}{9} & ER & 347.1 & 91.4 & 95.5 & 81.7 & 109.4 & 95.7 & 109.1 & 94.5 & 33.1 & 100.0 \\
\hline & PD & 259.1 & 68.2 & 58.7 & 50.2 & 80.1 & 70.1 & 92.2 & 79.9 & 28.1 & 84.9 \\
\hline \multirow[t]{2}{*}{10} & ER & 344.1 & 90.6 & 98.3 & 84.1 & 104.7 & 91.6 & 112.8 & 97.8 & 28.3 & 85.6 \\
\hline & PD & 298.5 & 78.6 & 69.0 & 59.0 & 97.1 & 85.0 & 104.3 & 90.4 & 28.1 & 84.9 \\
\hline \multirow[t]{2}{*}{11} & ER & 319.2 & 84.1 & 96.1 & 82.2 & 95.1 & 83.2 & 94.9 & 82.2 & 33.1 & 100.0 \\
\hline & PD & 264.7 & 69.7 & 79.1 & 67.7 & 83.2 & 72.8 & 83.2 & 72.1 & 19.2 & 58.0 \\
\hline \multirow[t]{2}{*}{12} & ER & 326.8 & 86.1 & 89.3 & 76.4 & 92.6 & 81.0 & 111.8 & 96.9 & 33.1 & 100.0 \\
\hline & PD & 190.6 & 50.2 & 55.6 & 47.5 & 29.9 & 26.2 & 85.5 & 74.1 & 19.6 & 59.4 \\
\hline 13 & $\begin{array}{l}E R \\
P D\end{array}$ & 357.0 & 94.0 & 100.5 & 85.9 & 114.3 & 100.0 & 109.1 & 94.5 & 33.1 & 100.0 \\
\hline \multirow[t]{2}{*}{14} & ER & 338.3 & 89.1 & 91.4 & 78.2 & 107.0 & 93.6 & 106.8 & 92.6 & 33.1 & 100.0 \\
\hline & PD & 274.5 & 72.3 & 73.9 & 63.2 & 82.8 & 72.4 & 89.7 & 77.7 & 28.1 & 84.9 \\
\hline \multirow[t]{2}{*}{15} & ER & 333.0 & 87.7 & 92.0 & 78.7 & 105.2 & 92.0 & 102.7 & 89.0 & 33.1 & 100.0 \\
\hline & $P D$ & 297.9 & 78.5 & 72.4 & 61.9 & 90.5 & 79.2 & 106.9 & 92.6 & 28.1 & 84.9 \\
\hline $\begin{array}{l}\text { The total numbe } \\
\text { supplemental). } \\
\text { group of "gene } \\
\text { used their ERs fo } \\
\text { PDs. All facilitie }\end{array}$ & $\begin{array}{l}f \text { points give } \\
\text { e points wer } \\
\text { resources", } \\
\text { eatment of } \\
\text { ith an item I }\end{array}$ & $\begin{array}{l}\text { y the int } \\
\text { btained } \\
\text { example } \\
\text { cally ill c } \\
\text { l of pres }\end{array}$ & ummi & $\begin{array}{l}\text { ed as "exper } \\
\text { score for the } \\
9 \text { items, havi } \\
\text { except one, } \\
6 \text { of the optin }\end{array}$ & $\begin{array}{l}\text { topin } \\
\text { differe } \\
\text { ng an } \\
\text { were s }\end{array}$ & $\begin{array}{l}\text { is appendix } \\
\text { op group r } \\
\text { opinion total } \\
\text { ntly equipped } \\
\text { old type. }\end{array}$ & $\begin{array}{l}\text { on the } i \\
\text { ging fro } \\
\text { ore of } 1 \\
75 \% \text { of }\end{array}$ & $\begin{array}{l}\text { nal web site } \\
1-5 \text {. This leve } \\
.9 \text { points. Ho } \\
\text { e experts opi }\end{array}$ & $\begin{array}{l}\mathrm{p}: / / \mathrm{w} \\
\text { ras alsc } \\
\text { ital nur } \\
\text { n) in c }\end{array}$ & $\begin{array}{l}\text { mionlin } \\
\text { d as a } \\
\text { s } 4,6 \text {, } \\
\text { arison }\end{array}$ & $\begin{array}{l}\text { level. The } \\
13 \text { only } \\
\text { of the } 11\end{array}$ \\
\hline
\end{tabular}

presence of the different item groups could be found at the expense of the PD.

\section{DISCUSSION}

ERs of the district general hospitals throughout the south west part of the Netherlands are far better equipped to meet the needs of critically ill paediatric patients than emergency facilities in the PDs. In some hospitals, the paediatricians involved in the treatment of children who become critically ill during their stay in the hospital (the "indoor" patients), have less equipment and medication on the PDs at their disposal than they have on their ER. In our opinion emergency care on the paediatric wards should be equipped at the same level as in the ER because for both locations the "golden hour" is critically important in the final outcome of these children.

In paediatrics, children of all ages may develop instability in vital signs in a comparatively short period of time. In the past three decades many new techniques and methods have developed to treat such patients. Since the introduction in the mid-1980s of the sub- specialisation of paediatric critical care by the American Board of Pediatrics, this sub-specialisation has matured and developed greatly. During this process, guidelines were developed, recommended, and reviewed. ${ }^{2} 5^{9-12}$ At the same time, the technological capacity to monitor and treat such paediatric patients has advanced rapidly. ${ }^{11}$ Together with these advances, there has been an evolution of paediatric intensive care units in tertiary care facilities. They are seen as the primary site for critically ill children. Many of those children however are primarily seen in district general hospitals. Similarly to the Netherlands, in the USA a committee, (of the American Academy of Pediatrics), provided guidelines for "furnishing and equipping" paediatric emergency facilities in community hospitals. ${ }^{4} 9$ Such a list of material and medication, based on expert opinion for its necessity, is a perfect tool to measure an inventory of paediatric emergency facilities, whether or not the children are coming from outside the hospital or from within.

To weight the list of necessary equipment we invited intensivists to provide us with their rating. The high number of paediatric intensivists that responded (79\%) made it possible to use the item list in the evaluation of the inventories as an "expert opinion". The experts assessed the presence of material to meet respiratory and circulatory problems along with the appropriate medication, the most essential part of the inventory (appendix 1). Interestingly, the district hospitals achieved the highest percentage score in these categories. This suggests that the general hospitals expect a maximal direct profit, in terms of morbidity and mortality, in an appropriate initial treatment of critically ill children with respiratory and/or circulatory problems. In our view however, the whole item list must be adequately present to create an optimum in inventory in places where critically ill children are initially treated. For example, medication to treat intoxicated children must also be available at site, independent of the frequency of occurrence. It is of interest that all hospitals in the south west part of the Netherlands, agreed to cooperate, indicating that a mutual desire exists in 
our region for the development of a better, possibly unified approach for the initial treatment of critically ill children.

When assessing the presence of the items within the different hospitals itself, important differences could be found. Regarding the total score, we found one ER that was not sufficiently equipped. This hospital is clearly below average because it depends only on its ER for initial care and does not have such a facility on the ward. Interestingly, four PDs had emergency facilities on their ward below the $75 \%$ norm for total score, with one facility even barely scoring $50 \%$. Assessing the two locations within one hospital for emergency care, the ER is most often better equipped than the PD. The fact that ERs are better equipped, totally and in terms of "general resources" could be the result of the influence of other medical specialists in the ERs, which is not true for PDs. Different training programmes like the advanced trauma life support have their positive influence on personnel and indirectly on the inventory on the emergency sites where they are working. ${ }^{13}$ Other specialists than paediatricians, for example, often also use chest tubes and resuscitation boards, so the chance that they are part of an inventory is higher in an ER than in a PD. In general, in a PD only paediatricians decide whether items are present or not.

Four hospitals decided only to use their ER for primary treatment. In such cases we would expect an optimum inventory, however in only two of these four ER, all item groups were sufficiently present with a high average score. In the remaining 11 hospitals, both the ER and PD are used for initial treatment for all children either from outside or inside the hospital. These findings are somewhat concerning, given the expert opinion and the list of items as agreed upon by the paediatricians working in the south west part of the Netherlands, it seems difficult to accept that facilities for emergency care are not all optimally equipped. Protocols and inventories should be followed especially when it concerns critically ill children.

Thus, comparing the differences in inventory between the ERs and the PDs, it is obvious that ERs are better equipped for initial treatment of critically ill "outdoor" children. Based on these findings, it seems that in some hospitals, it would even be better to treat "indoor" critically ill children in the ER of the hospital. The results of this study suggest that an upgrading of several facilities is clearly needed. This study is only a one moment assessment of the facilities but a regular evaluation is considered essential to be prepared for the critically ill children.

In addition to optimal equipment, it is obvious that other factors like the presence of experienced personnel to provide the care to those critically ill children are of particular interest. Having a good and well trained organisation of care within and between the hospitals is also an important factor for the quality of care. A study into such factors in the different district general hospitals in the south west part of the Netherlands is currently underway.

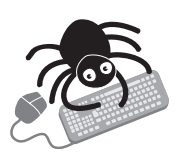

The appendices are available to view on the journal web site (http://www.emjonline.com/supplemental). Appendix 1 shows the point system used in the study. Appendix 2 gives the drug groups.

\section{Authors' affiliations}

N Van der Lely, P J C van Marion, J Otto, Department of Paediatrics, Reinier de Graaf Gasthuis, Netherlands

J A Hazelzet, H A Büller, Department of Paediatrics, Sophia Children's Hospital, Erasmus Medical Centre Rotterdam, Rotterdam, Netherlands

Funding: this study was supported by the Research Foundation Delft (grant no WAC 9802).

Conflicts of interest: none declared.

\section{REFERENCES}

1 Pollack MM, Alexander SR, Clarke N, et al. Improved outcomes from tertiary center pediatric intensive care: a statewide comparison of tertiary and nontertiary care facilities. Crit Care Med 1991;19:150-9.

2 Thompson DR, Clemmer TP, Applefeld JJ, et al. Regionalization of critical care medicine: task force report of the American College of Critical Care Medicine. Crit Care Med 1994;22:1306-13.

3 Luft HS. Regionalization of medical care. Am J Public Health 1985;75:125-6.

4 American Academy of Pediatrics Committee on Pediatric Emergency Medicine. Guidelines for pediatric emergency care facilities. Pediatrics 1995;96:526-7.

5 American Academy of Pediatrics, Committee on Pediatric Emergency Medicine and American College of Physicians, Pediatric Committee. Care of children in the emergency department: guidelines for preparedness. Pediatrics $2001 ; 107: 777-81$.

6 American Academy of Pediatrics, Committee on Pediatric Emergency Medicine, American College of Critical Care Medicine, Society of Critical Care Medicine. Consensus report for regionalisation of services for critically ill or injured children. Pediatrics 2000;105:152-5.

7 Siegel E, Gillings D, Campbell S, et al. A controlled evaluation of rural regional perinatal care: impact on mortality and morbidity. Am J Public Health 1985;75:246-53.

8 Clemmer TP, Orme JF Jr, Thomas FO, et al. Outcome of critically injured patients treated at level I trauma centers versus full-service community hospitals. Crit Care Med 1985;13:861-3.

9 American Academy of Pediatrics, Committee on Hospital Care. Facilities and equipment for the care of pediatric patients in a community hospital. Pediatrics 1998;101:1089-90.

10 Guidelines Committee of the American College of Critical Care Medicine, Society of Critical Care Medicine and American Association of Critical-Care Nurses Transfer Guidelines Task Force. Guidelines for the transfer of critically ill patients. Crit Care Med 1993;21:931-7.

11 Committee on Hospital Care of the American Academy of Pediatrics and Pediatric Section of the Society of Critical Care Medicine. Guidelines and levels of care for pediatric intensive care units. Pediatrics 1993;92:66-175.

12 Gemke RJ, van der Voort E, Bos AP. The necessity for centralization of pediatric intensive care. Ned Tijdschr Geneeskd 1997;141:2325-7.

13 Kennedy DW, Gentleman D. The ATLS course, a survey of 228 ATLS providers. Emerg Med J 2001;18:55-8. 